the Indian operation gives superior results to the capsulotomy operation. But the author fails to point out that all the most suitable cases were operated upon by the intra-capsular method, and only the poor chances done with capsulotomy. This fact, of course, vitiates the statistics. Also it is a very great mistake to think that what is suitable for India is good for home consumption. After operating in Jerusalem, I was most disagreeably surprised when I began in England to find that I was faced with such complications as irido-cyclitis, that $I$ had never seen in Palestine.

\title{
DIABETES AND THE EYE
}

This was the subject of discussion at a meeting of the Clinical Society held at the Royal Eye Hospital on July 16, 1943.

Miss Orr-Ewing, the Chairwoman, welcomed the visitors. She said that bricks and mortar might be destroyed; but never the democratic Royal Eye spirit. At these meetings all were equal. The Honoraries had no privileges; but if they took part must stand on their own merits. She thanked Dr. Lawrence, the principal speaker, for his kindness in coming to the meeting. $\mathrm{He}$ would be listened to with great attention, and might expect a barrage of questions and possibly criticisms.

Dr. Lawrence said that before describing the changes he had observed in many thousands of diabetic eyes, he proposed to give a brief outline of what the diabetic defective metabolism is and particularly what changes it makes in relation to the physiology of the eye. Normal people had got 100 milligrams per cent. of sugar in their blood in the fasting condition; after a meal containing carbohydrate-sugar, cakes, buns, etc.-the blood sugar rises for an hour or two, but practically never goes above 170 milligrams per cent., from absorption of sugar from the gut into the circulation. When this increased blood sugar reaches the pancreas it stimulates the production of sufficient insulin to burn and store this excess of sugar so that the blood sugar rapidly returns to normal. In diabetes, the production of insulin is defective, the blood sugar rises to 2,3 , or 4 times the normal, sugar spills into the urine and the typical symptoms of diabetes are produced by two main factors-the loss of the nourishing carbohydrate food, and dehydration-which always follows heavy glycosuria.' When this loss of sugar becomes very heavy and the insulin production so low that little carbohydrate can be burned, then a secondary disturbance of fat metabolism occurs, known as ketosis - when acetone bodies appear in the urine, cause, and lead through stages of air hunger, vomiting, etc., to death through diabetic coma. During ketosis the intense 
polyuria, vomiting, etc., greatly increases the loss of water, and dehydration becomes severe.

The treatment is simple enough in theory and in mild cases the restriction of carbohydrate-diet alone-may enable the remaining insulin of the pancreas to deal with sufficient carbohydrate to keep the urine sugar-free, the blood sugar approximately normal and the patient in good health. More severe diabetics have not even this minimal production of insulin and must be treated by injections of insulin prepared from animals. This may be given twice a day-in the form of the old, soluble, insulin, or once a day of the newer, protamine insulin which acts slowly and certainly for 24 hours. All accepted diabetic cases, however severe, can be kept well and in proper nutrition by the proper use of diet and insulin: The chief facts that concern the eyes are the poor healing qualities of the untreated diabetic and secondly, and perhaps more obviously, changes produced by dehydration and withdrawal of water from the eye.

A great number of changes have been observed in diabetes and though some of them are clearly due to. the above factors, the aetiology of retinal changes is still completely obscure. The following are the chief changes observed by the use of the ophthalmoscope alone in some 10,000 diabetic cases, the majority of which have had a fairly careful eye examination by myself or colleagues.

1. Curious focusing changes in accommodation are found at some stage in most diabetics, if careful enquiry is made. Usually when acute diabetes is coming on myopia develops and persists for some 3-10 days when, in spite of no treatment and the continuation of the diabetic state-high blood sugar, glycosuria, etc., this disappears and the focus comes back to its previous state. On the other hand, when this excess of sugar is removed and the patient desugarised, either by diet, or diet and insulin, the opposite frequently occurs - hypermetropia develops (even up to +9 dioptres), the patient cannot read at all, and becomes greatly alarmed. This change too is temporary and disappears in about 10. days. There are no visible changes in the lens or different media of the eye and a full explanation of the phenomenon cannot be given, but it is obviously due to water or colloid changes, perhaps more in the vitreous than in the lens. At any rate, it is a grave mistake to fit these patients out with glasses which may be necessary for a day or two only and completely wasted later on. With such cases it has been my practice to supply them with some suitable Woolworth's glasses out of a box until they do not need them-a practice of which ophthalmologists may not approve!

2. Severe dehydration in precomatose conditions produces 
great water changes in the eyes, the signs of which are very clear, but, of course, are seldom seen by ophthalmologists. The eye tension becomes extremely low and is quite diagnostic of diabetic coma. In some cases the eyeball can hardly be felt to the examining finger and $\mathrm{Mr}$. Eric Lyle measured the tension in one case as only 7 millimetres of mercury (Schiotz).

I have described* the curious changes that can be seen in the lens, presumably from the withdrawal of water from it and shrinkage of its contents : the capsule looks wrinkled and quite dark opacities-becoming even total before death-can be seen with a +15 D. lens of the ophthalmoscope. With treatmentinsulin and the replacement of body fluid - these changes rapidly disappear and leave no permanent effects. It is probable that a similar process takes part in the production of diabetic cataracts.

I have seen a few cases of the condition of rubeosis iridis which appears to be a complication unique to diabetes, but I am not in a position to know whether iritis and glaucoma are, on the whole, commoner in diabetics than in normal people.

Lens changes and opacification may be divided into two categories : the first, acute cataracts, which -may develop within a few days-or certainly weeks-occur in young cases, children and adolescents, and, in my experience have developed in badly controlled cases. I have seen only a dozen of such cases and never seen them improved by diabetic treatment. When first seen opacification had occurred and most of these cataracts rapidly become opaque and require operation, which gives very good results. The second is the type of cataract which develops in so many elderly diabetics and there is still a dispute how much they are senile and how much they are diabetic-into which I shall not enter. The vast majority can be successfully operated on and in my experience the results are good, there being certainly no undue incidence of sepsis or haemorrhage. I gather that this is more likely to occur in badly controlled cases but as most of my patients are fairly well controlled under observation, I do not know what effect good or bad control has on the results and would .be interested to hear the opinion of those present.

Retinitis is the complication I fear almost most in diabetics and it is extremely common. I have not gone fully into the statistics of my cases, but think 15 per cent.-mostly elderlyhave this complication and in many it is already established when diabetes is first diagnosed. I am certain it occurs mostly in longstanding uncontrolled mild cases, and diabetics of short duration or under good control from the start develop it far less commonly. It has been disputed whether there is a true diabetic retinitis without arteriosclerotic or renal complicating factors. I have seen

${ }^{*}$ Lancet, p. 63, July 18, 1942. 
hundreds of cases, however, with no other factors than sugar when the retinitis was discovered and am convinced of the reality of the syndrome. The first manifestations are punctate haemorrhages from venous radicles, deep in the retina and later, light exudates almost anywhere; later on the latter become intensely hard, white and thick, often edged with black pigment and very different from renal manifestations. Once the process is established it is checked, but not cured, by good diabetic control, and most of these cases retain moderate eyesight for many years although a few cases develop retinitis proliferans and go completely blind. It seems quite certain ,that the lesions are on the venous side of the vascular tree, that they occur through a damaged epithelium-exact cause unknown - but their frequency must be due to the relatively high venous tension (over $20 \mathrm{~mm}$. mercury) which exists in the venous system of the eyes. Here is a great field for research.

I have seen about 10 cases of retrobulbar neuritis, clinically indistinguishable from tobacco amblyopia ; 4 of them have occurred in non-smokers and were directly due to severe diabetes. In most cases the vision rapidly improves and, indeed, becomes normal when early and adequate diabetic treatment is given.

A not uncommon occurrence in diabetes is diplopia, usually from VIth nerve neuritis, again mostly in elderly cases and not necessarily accompanied by arteriosclerosis; they all get better in some 6-10 weeks, in my experience.

Finally, mention must be made of the functional changes that occur in vision during attacks of hypoglycaemia. When the blood sugar is reduced too low by an overdose of insulin, diplopia, misty vision, "flashes of light" and many quaint varieties of visual disturbances may occur and are often the first signs by which patients recognise the attack. There are no changes to be observed within the eyes and the basis of these disturbances is definitely in the brain cells whose function depends directly on glucose metabolism which is temporarily absent in hypoglycaemia.

These are the main changes I have noticed and the only ones I need outline. There is, however, one more point to which I should like to draw your attention. Most ophthalmologists I meet do not test urines nor take blood pressures and I do not see how without doing this they can come to an accurate diagnosis, increase their knowledge, and help the patients. It is not infrequent for me to see a patient in whom retinal haemorrhages had been recognised two years before, the case referred back to the doctor, but often the patient takes no further notice and in another year or two the retinitis has progressed so far without any treatment that the eyesight is already seriously damaged. 
Miss Orr-Ewing said she personally had learnt much from this most excellent lecture, which cleared up many points of confusion in her mind. The lecture was now open to discussion.

Mr. J. M. Bickerton wondered if Dr. Lawrence had not laid perhaps a little excessive stress on the venous character of the retinal haemorrhages. He himself had often noted arterial haemorrhages. Quite frequently it was hard to say from what type of vessel a small haemorrhage was coming.

Dr. Wilfrid Oakley asked why so many "eye men were chary of operating on diabetics, especially those with retinitis. He had one patient, blind with cataract; and several surgeons turned down the case. Eventually one, bolder than the rest, operated. In spite of the retinitis the visual result was verr satisfactory to the patient. Did diabetics really do much worse than the generality of cases? Did careful control of the glycosuria really count for as much as was claimed? He had always taken meticulous care in his own cases; but wondered what would have happened if he had not been so careful.

Mr. Savin said that he was quite sure that lax control of the diabetes made results of operations much worse. There was much more post-operative iritis. Even in well-controlled diabetes post-operative iritis was a problem. That was partly why he now preferred intracapsular extractions for diabetic cataracts. He did not think diabetics bled much more than other folk. In his hands they took longer in hexling.

He had seen one case of the wrinkled lens capsules of dehydrated diabetics which Dr. Lawrence described. In that case there was also wrinkling of Descemet's membrane.

Myopia in early diabetes could be a pitfall. He had fallen into the error of prescribing glasses for it, with subsequent complete alteration of the refraction when the diabetes was controlled.

He had been most unsuccessful in the treatment of rubeosis iridis and its sequel of glaucoma. Riboflavine did not seem to help and operation often proved disastrous.

Dr. Alkan said he thought it a fallacy. to say that well-controlled diabetics healed more slowly than other cases. He asked whether lens opacities ever regressed under efficient diabetic treatment.

Mr. Lipschutz asked how the course of diabetic retinitis was affected by treatment?

Miss Lingfield asked whether vitamin $\mathrm{K}$ did any good in these cases?

Dr. Brigden stressed the importance of excluding other neurological conditions before diagnosing diabetic retrobulbăr neuritis.

Dr. Lawrence in reply stated that he had no doubt arterial haemorrhages could often be discovered in those patients with concurrent arteriosclerosis. Nevertheless he thought the typical haemorrhage venous in origin. Many of his diabetic patients had had cataract extractions in many surgical hands. He was sure they were not often troubled by sepsis, perhaps through the pre-operative precautions taken. He could not claim sufficient acquaintance with normal cataract extractions to say whether diabetics were really more liable to haemorrhage. It was usually worth while removing an opaque lens, even where there was retinitis. Partly blind patients were grateful for small improvements. Treatment did not necessarily improve retinitis where established. He certainly thought retinitis patients travelled less rapidly towards blindness when under adequate treatment of their diabetes. He did not think lens opacities ever improved under medical treatment once protein coagulation had taken place in the opacity. Mere water clefts in a lens could of course disappear under treatment. Vitamin $K$ had been extensively tried in diabetic retinitis. From what he read and could hear, it seemed of little value. With regard to the diagnosis of diabetes by the ophthalmoscope, he wished eye men would more frequently check up their suspicions of diabetes by testing urine and blood-pressures themselves. An early diagnosis of diabetes was of incalculable assistance to the patient. 